\title{
Variations In The External Morphology Of Gall Bladder: A Cadaveric Study In South Coastal Population.
}

\author{
Chakka Sreekanth ${ }^{1}$, Makani Thanuja Kumari ${ }^{2}$, Lattupalli Hema ${ }^{3}$, \\ ${ }^{I}$ Associate professor of anatomy, Sri Padmavathi Medical college for women, SVIMS Tirupathi. \\ ${ }^{2}$ Assistant professor of anatomy, Narayana Medical College, Nellore \\ ${ }^{3}$ Professor and head of anatomy, Narayana Medical College, Nellore.
}

\begin{abstract}
Background: The extra hepatic biliary apparatus usually presents with some anatomical or embryological variations which go unnoticed and are commonly encountered during some radiological investigations or in operation theaters. Such variations of the morphology of Gall bladder have been well documented in the literature for many years but a detail morphological study of variations of the gall bladder and its incidence is very rare. In this era of quick results, increasing use of diagnostic and interventional procedures makes it important to study variations of gall bladder morphology. Most of the interventional procedures in this modern era are done laparoscopically and there is tremendous increase in the number of laparoscopic cholecystectomies. So, sound knowledge of possible variations in morphology of gall bladder is important.

Materials and Methods: This study was undertaken on 100 cadaveric liver and gall bladder specimens in terms of length, maximum transverse diameter, and shape, external variations of gall bladder, Interior and length of gall bladder below the inferior border of the liver.

Results: Gall Bladder had length ranging between 3.3 and $10 \mathrm{~cm}$, transverse diameter between 2.0 and $5.0 \mathrm{~cm}$. The commonest shape observed in this study was pear shaped in $80 \%$ of cases. The length of gall bladder below the inferior border of liver varied between 0.4 and $2.5 \mathrm{~cm}$.

Conclusion: The growing importance of such variations, lie not only from the point of biliary disease but also with respect to the various invasive techniques in the diagnosis and treatment of gall bladder and extra hepatic bile duct disease.
\end{abstract}

Keywords: Cholecystectomies, Laparoscopically, Variations, Interventional, Malformations, external variations, shapes of gall bladder.

\section{Introduction}

The gall bladder (GB) is a pear shaped hollow viscus, slate blue in colour situated obliquely in a non peritoneal fossa on the under surface of the right lobe, and extends from the right end of porta hepatis to the inferior border of liver. It measures about $7 \mathrm{cms}$ to $10 \mathrm{cms}$ in length, maximum breadth being $3 \mathrm{cms}$ and capacity is $30-50 \mathrm{ml}$. The presenting parts of gall bladder are from below upwards and downwards: fundus, Body and Neck. The fundus is the lower expanded free end of the gall bladder which projects below the liver. It is directed downwards, forwards and to the right meeting the anterior abdominal wall at an angle of $30^{\circ}$. It is invested by peritoneum on all sides. The body of gall bladder extends from the fundus to the neck, and is directed upwards, backwards and to the left. Upper surface of the body is non peritoneal, and the lower surface and sides are covered by peritoneum. The neck forms an S shaped curve and extends from the body to the cystic duct. At first the neck passes upwards and forwards, then turns abruptly downwards and backwards, and is continuous with the cystic duct separated by a constriction. From the neck a small diverticulum known as Hartmann's pouch sometimes projects downwards and backwards towards the duodenum .the portion of the neck giving attachment to Hartmann's' pouch is sometimes called the "ISTHMUS OF GALL BLADDER."

Though human beings are thought to be singularly thought to be alike in their general anatomic construction, yet we come to investigate one particular region with more detail, it is surprising how frequent we meet one sort or another type of variation. This is also very true in case of anatomy of extra hepatic biliary apparatus, that according to some eminent workers, there is no normal anatomy of extra hepatic biliary tract instead, a common pattern of variations exist and it is the surgeons duty to be familiar with and recognize the normal variations when present [2]. Anomalies of the extra hepatic biliary apparatus can arise from the gall bladder, cystic duct, hepatic duct and the common bile duct and it is imperative to be familiar with them in order to avoid the disastrous consequences during surgeries.

It is very much essential to have a basic knowledge regarding the development and normal anatomy of biliary tract which gives us a fuller understanding of the anatomical and embryological anomalies. The knowledge of these variants will make the laparoscopic procedures easier, though preoperative diagnosis sometimes goes un seen in few cases, which in turn is an unexpected finding during laparoscopic surgeries. This 
Variations In The External Morphology of Gall Bladder: A Cadaveric Study In South Coastal..

study will be an addition to the literature and will create awareness among anatomists, radiologist, to surgeons and also gastroenterologist medical and surgical to be thorough regarding the normal and abnormal aspects of Gall Bladder

\section{Materials And Methods}

This study was carried on 100 liver and gallbladder specimens obtained from $10 \%$ formalin fixed cadavers in the Department of Anatomy of Narayana Medical College, Nellore. Cadavers with obvious abdominal surgery and crush injury to the abdominal organs were excluded from the study. The parameters studied were the maximum length of gall bladder, maximum transverse diameter, shape, external variations of gall bladder, Interior, Level i.e. length of gall bladder below the inferior border of the liver. Maximum length and maximum transverse diameter was measured using metallic measuring tape gradated in centimeters. The shape of gall bladder was noted down. Any variation in external appearance of gall bladder was also noted. Part of the gall bladder i.e. fundus that lie below the inferior border of liver was noted. Interior of gall bladder was also visualized to see any abnormality by cutting across its wall with the help of a scalpel blade.

\section{Results}

Maximum length of gall bladder: Average length of gall bladder was found to be $10 \mathrm{~cm}$. The smallest gall bladder was $3.3 \mathrm{~cm}$ in length and the largest had length $12 \mathrm{~cm} .48 \%(48 / 100)$ GB had length ranging between 7 and $10 \mathrm{~cm}$.

\section{Maximum transverse diameter of gall bladder}

Mean breadth of gall bladder was $3.46 \mathrm{~cm}$. The shortest transverse diameter was $2.0 \mathrm{~cm}$ and largest $5.0 \mathrm{~cm} .68 \%$ (68/100) GB had a maximum transverse diameter between 2 and $5 \mathrm{~cm}$.

\section{Shape of gall bladder:}

The gall bladders were classified according to their shapes. Various shapes observed were pear shaped, cylindrical shaped, hourglass shaped, retort shaped, flask or irregular shaped. The commonest shape found was pear shaped $(80 / 100,80 \%)$.

\section{External appearance of gall bladder:}

Foldings of neck and fundus (whether anteriorly or posteriorly) were noted. Folding of neck or fundus was noted in 6 out of 100 specimens of GB.

Length of gall bladder below inferior border of liver:

The length of gall bladder below the inferior border of liver varied between 0.4 and $2.5 \mathrm{~cm}$.

\section{Interior of gall bladder:}

In most of the gall bladders, interior was found to be normal with numerous rugosities of the mucosa. Gall stones were not observed in any of the specimens either singly or in multiples, but calcified structures were found singly but we could not differentiate it. Mucosal adhesions and septa were observed.

\section{Discussion}

The gall bladder, liver and the biliary ductal system develop from the hepatic endodermal diverticulum of the foregut, at the beginning of the fourth week of development. This diverticulum rapidly proliferates into the septum transversum and divides into two parts - the cranial part develops the liver and the bile ducts while the caudal part gives rise to the gall bladder and the cystic duct. Any arrest or deviation from the normal embryological developmental process may result in some sort of malformation of the gallbladder and of the biliary system [2].

The measurements of length and breadth of gallbladder were very similar to that found by Shari RS and Shah SA1 (2008) and Jaba Rajguru et al (2012). Comparison of length and breadth with other workers has shown in table I. Size of gall bladder varies in different diseased conditions as well as in some physiological conditions too. It may be impossible sometimes to distinguish between various parts described. The size of GB may increase after vagotomy, diabetes, Pregnancy, sickle cell disease, after cystic duct or common bile duct obstruction [2].

Shapes of GB vary tremendously and various authors have described various shapes. The terminologies describing the shape are also very Confusing. We found pear shaped GB as most common in 80 patients $(80 \%)$. Jaba Rajguru et al [2] noted pear shaped gall bladder in 85\% Specimens. Holinshed [3] (1983), Shaher [4] (2005), Moore and Dalley [5] (2006), Chari and Shah [1] (2008) noted various shapes of GB.

The gall bladder is relatively constant in its development and the two most significant variations are the folded fundus and variation at the neck of the gall bladder [3]. The folded fundus of the gall bladder, also called as the Phrygian cap, was reported in 3-7.5\% of GB by Lichtenstein \& Nicosia [6] (1955). They proposed that it could due to a disproportion between the size of the gall bladder and that of the gallbladder bed, but without any pathological significance [2]. 
Variations In The External Morphology of Gall Bladder: A Cadaveric Study In South Coastal..

In our study, we found folded fundus in 2 GB (2\%) and folded neck in 4 GB (4\%) folded fundus and neck 02 (02\%). Deutsch7 (1986) and Gore et al [8] (2000) recorded folded fundus in very few percentage of GB [2].The length of Gall bladder below the inferior border of the liver in our study was found to be ranging between 0.4 and $2.5 \mathrm{~cm}$. This is the most susceptible part of GB that can be damaged in laparoscopic procedures.

The interior showed adhesions and septa. Septum was observed in only 2 GB (2\%). Csepel et al (2003), Chalkoo (2009) and Talpur et al (2010) also observed septum in some gall bladders [2]. In our study, five gall bladders $(5 / 100,5 \%)$ showed the presence of stones in its interior. However congenital anomalies of gallbladder are rare and can be accompanied with other biliary and vascular malformations [9]. Due to these anatomical variations, complications seen were bleeding and biliary leaks leading morbidity [10].

\section{Conclusion}

The occurrence of cluster of congenital anomalies and anatomical variations of gall bladder and extrahepatic biliary tree though are not common but can be of clinical importance and surprising to the surgeons if present. But the literature regarding morphological variations of the gall bladder and their incidence is scarce. These variations generally remain symptoms free but often lead to complications and therefore must be correlated clinically. Awareness of these anomalies will decrease morbidity, and re exploration in such patients. Most of the interventional procedures in this modern era are done laparoscopically and there is tremendous increase in number of laparoscopic Cholecystectomies. So, thorough knowledge of possible variations in morphology of gall bladder is important. This article will be of utmost useful to the surgeons to understand and identify possible variations of GB morphology.

\section{References}

[1]. Chari RS, Shah SA. Biliary System In:Townsend CM, Beauchamp RD, Evers BM,Mattox KL. Sabiston Textbook Of Surgery. 18th Ed; St. Louis, Mo: WB Saunders; 2007:Chap. 54; 1474-14

[2]. Jaba Rajguru, Satyam Khare, Shilpi Jain, Rashmi Ghai, Mukesh Singla, Prabhat Goel. Variations In The External Morphology Of Gall Bladder. J. Anat. Soc. India 2012;61(1)9-12.

[3]. Hollinshed WH. Anatomy For Surgeons In The Liver And The Gall Bladder, 3rd Ed; Vol. 2; Harper And Row, Philadelphia, 1983, 334.

[4]. Shaher Z: Gallbladder Anomalies; Agenesis, Hourglass, And Liver Tissue Migration: Amultimedia Article. The Internet Journal Of

[5]. Surgery. 2005; 6(2): P. 9

[6]. Moore KL And Dalley AF. Clinically Oriented Anatomy In Abdomen . 5th Edn, Lippincott Williams \& Wilkins, Philadelphia,2006 , 302 .

[7]. Lischtenstein M, Nicosia AJ The Clinical Significance Of Accessory Hepato-Biliary Ducts. Annals Of Surgery. 1955; 141 (1):120124.

[8]. Deutsch AA, Englestein D, Cohen M, Kunichevsky M, Reiss R. Septum Of The Gallbladder, Clinical Implications And Treatment. Postgrad Med J. 1986; 62: 453-56.

[9]. Gore RM, Fulcher AS, Taylor AJ, Ghahremani GG. Textbook Of

[10]. Gastrointestinal Radiology, In Anomalies And Anatomic Variants Of The Gallbladder And Biliary Tract. 2nd Ed. WB Saunders Co,

[11]. Philadelphia, PA;2000;1305-20.

[12]. Carbajo MA, Martin Del Orono JC, Balanco JI, Cuestac, Martin F, Toledano M, Et Al.Congenital Malformations Of Gallbladder And Cystic Duct Diagnosed By Laparoscopy: High Surgical Risk. JSLS 1999; 3: 319-21.

[13]. Khamiso Altaf Hussain Talpur Et Al.Anatomical Variations And Congenital Anomalies Of Extra Hepatic Biliary System Encountered During Laparoscopic Cholecystectomy. J Pak Med Assoc; 2010; 60(2): 89-93.

\section{SMALL GALL BLADDER}

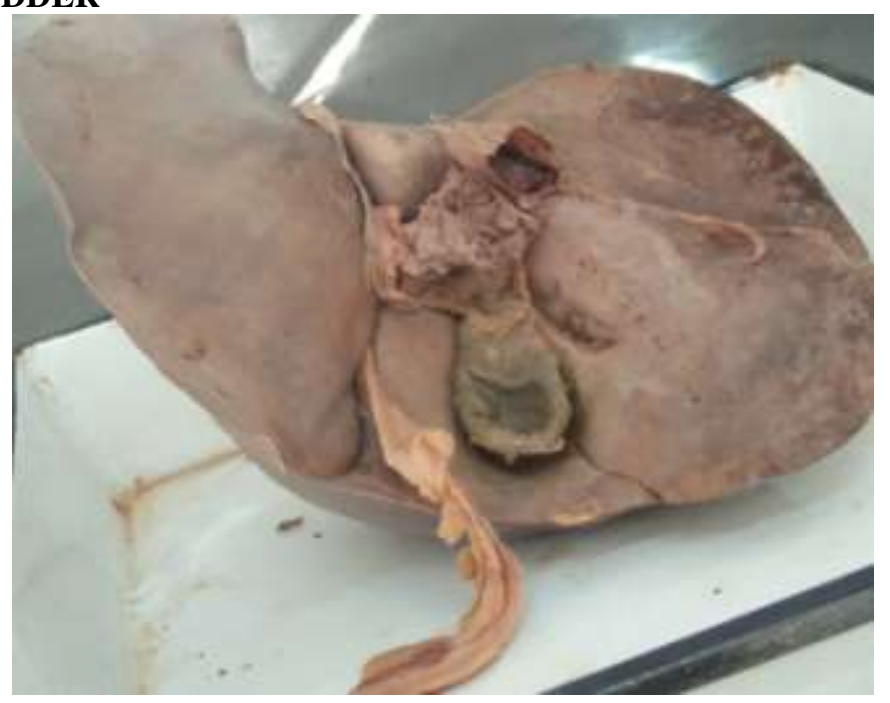


Variations In The External Morphology of Gall Bladder: A Cadaveric Study In South Coastal..

\section{IRREGULAR SHAPED GALL BLADDER}

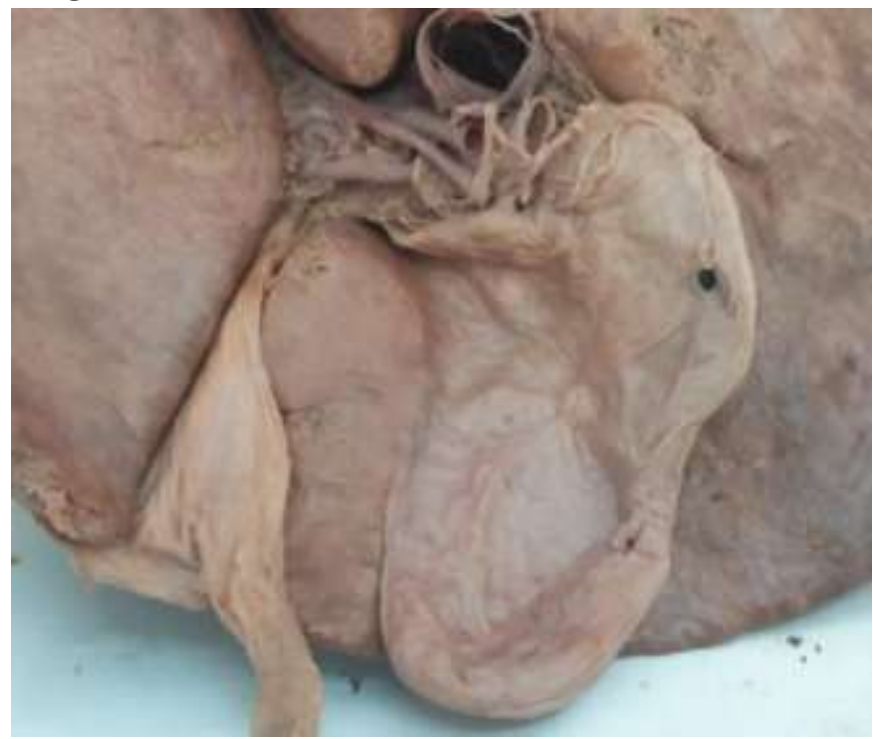

\section{CYLINDRICAL SHAPED GALL BLADDER}

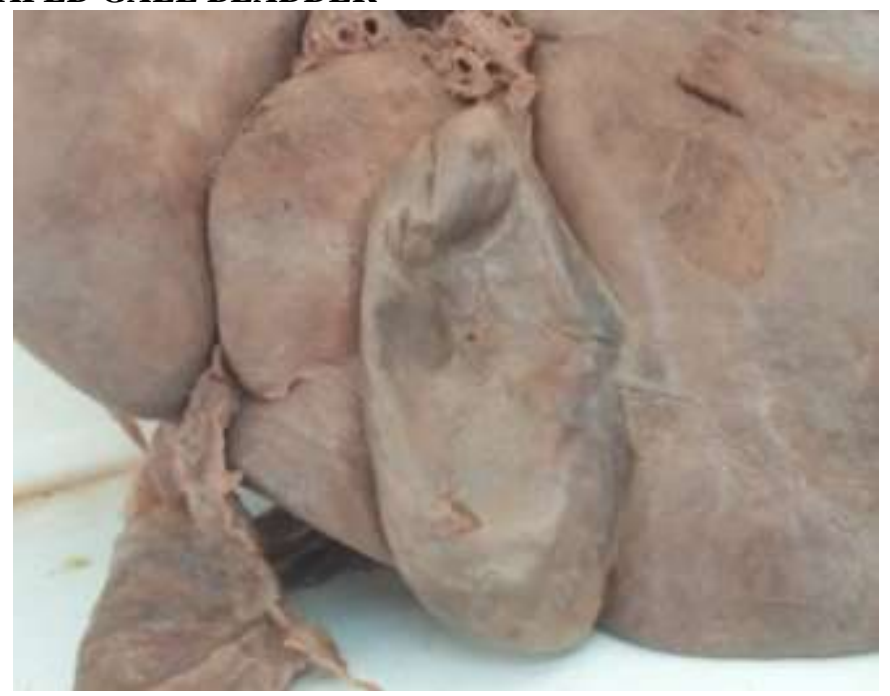

\section{RETORT SHAPED GALL BLADDER}

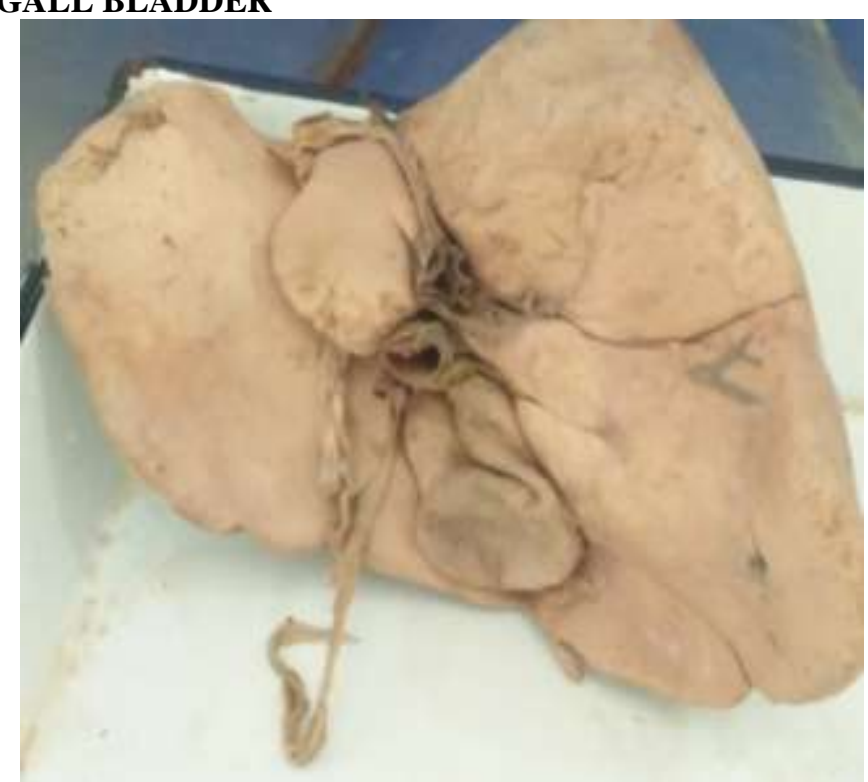


Variations In The External Morphology of Gall Bladder: A Cadaveric Study In South Coastal..

\section{FLASK SHAPED GALL BLADDER}

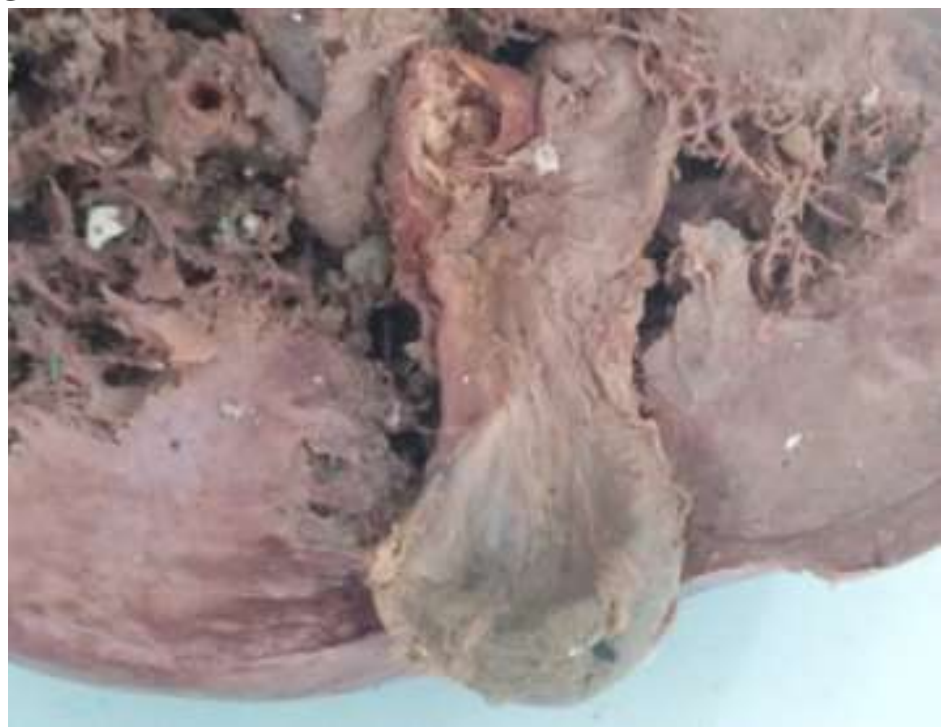

6. HOUR GLASS SHAPED GALL BLADDER

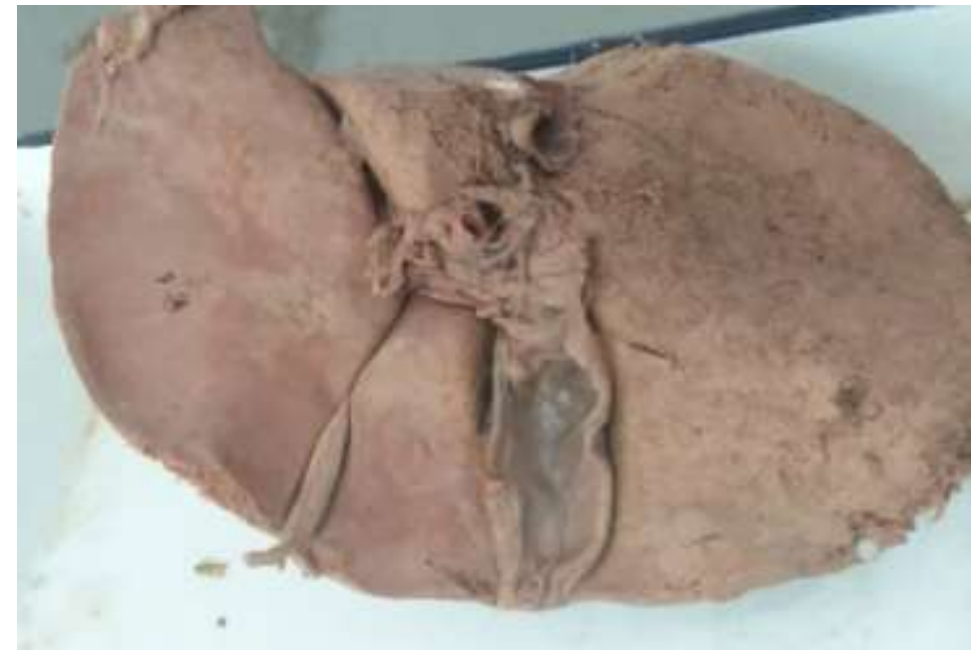

7. FUNDUS FOLDED ANTERIORLY

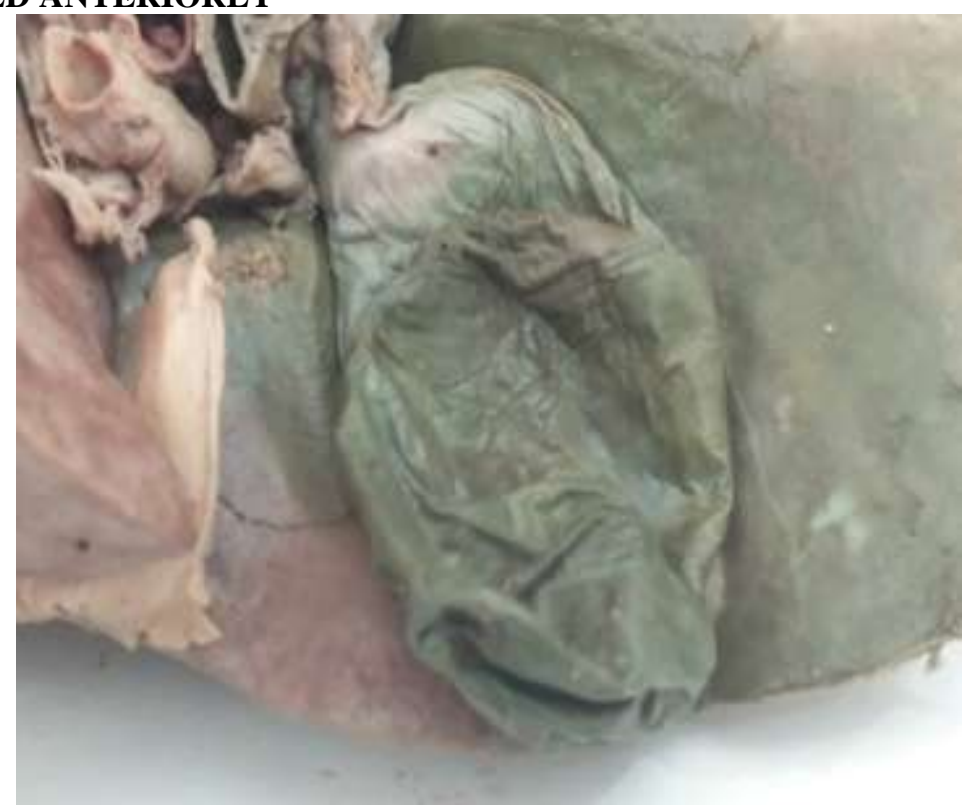


Variations In The External Morphology of Gall Bladder: A Cadaveric Study In South Coastal..

\section{PHYRGIAN CAP}

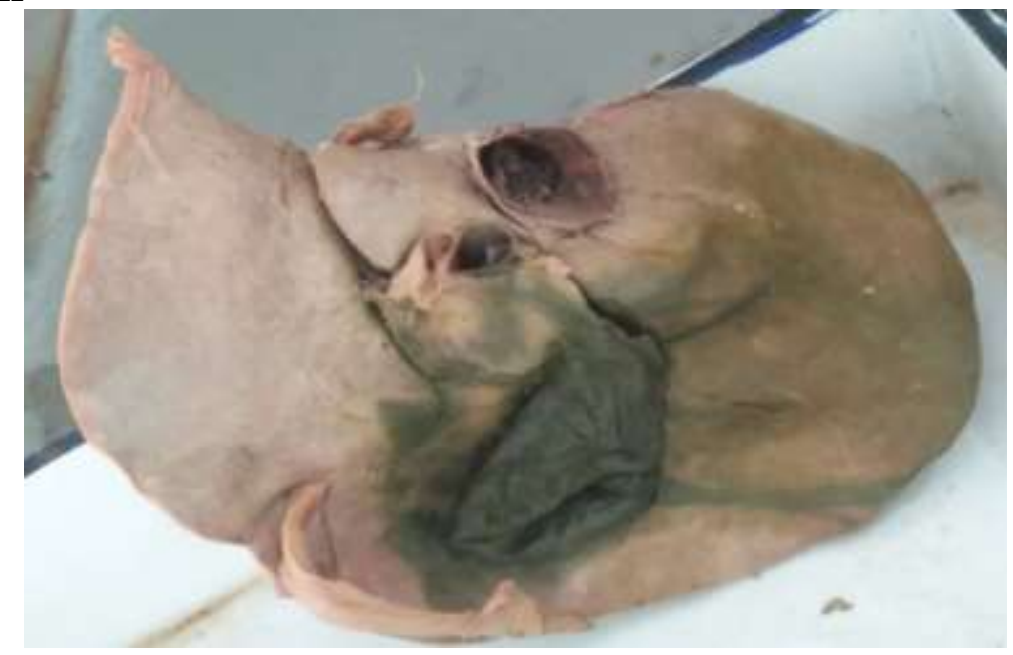

\section{FOLDED NECK POSTERIORLY}

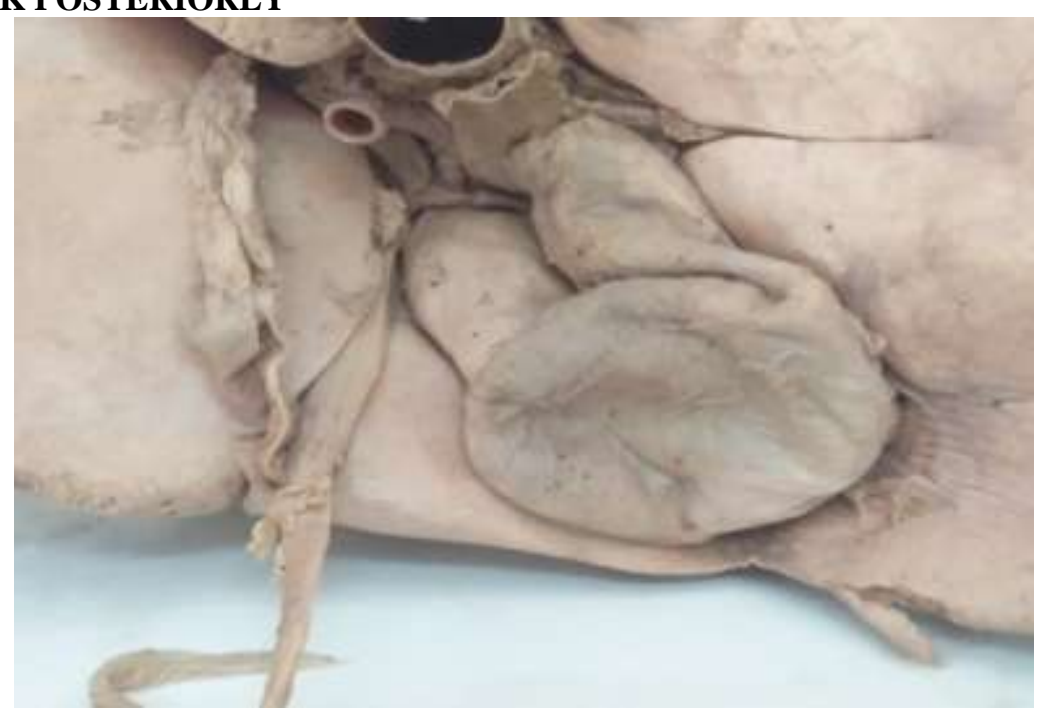

10. FOLDED NECK ANTERIORLY

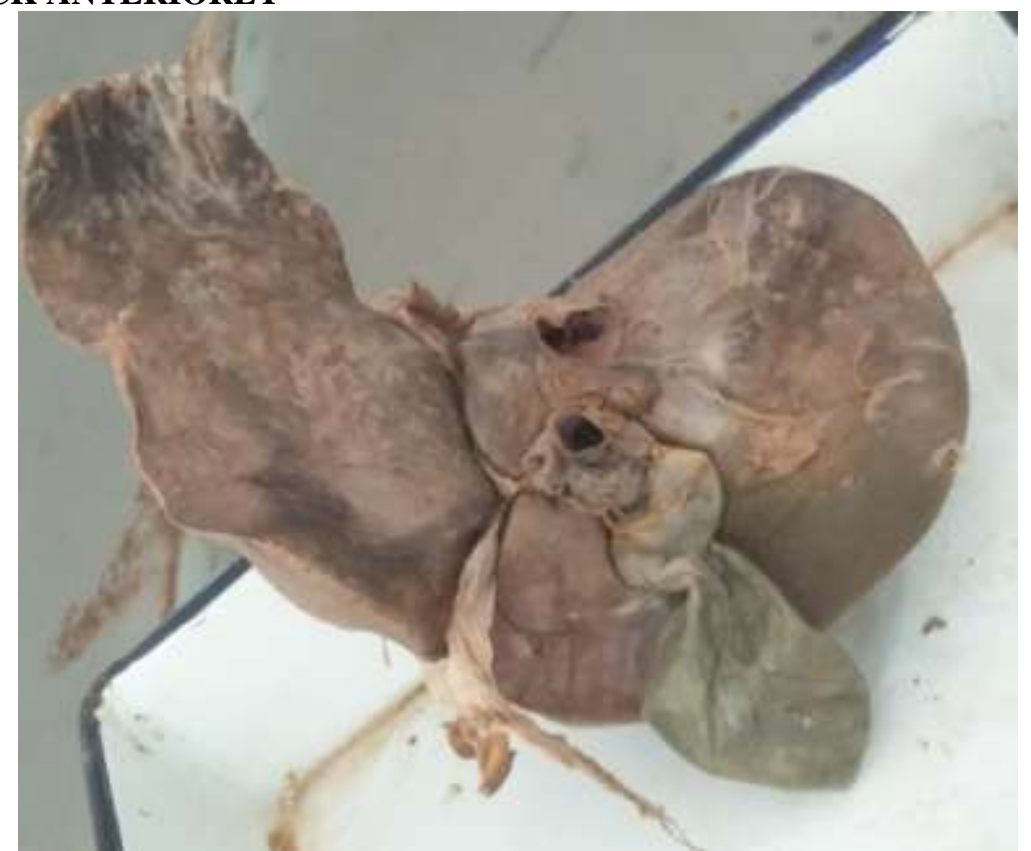




\section{LARGE GALL BLADDER}

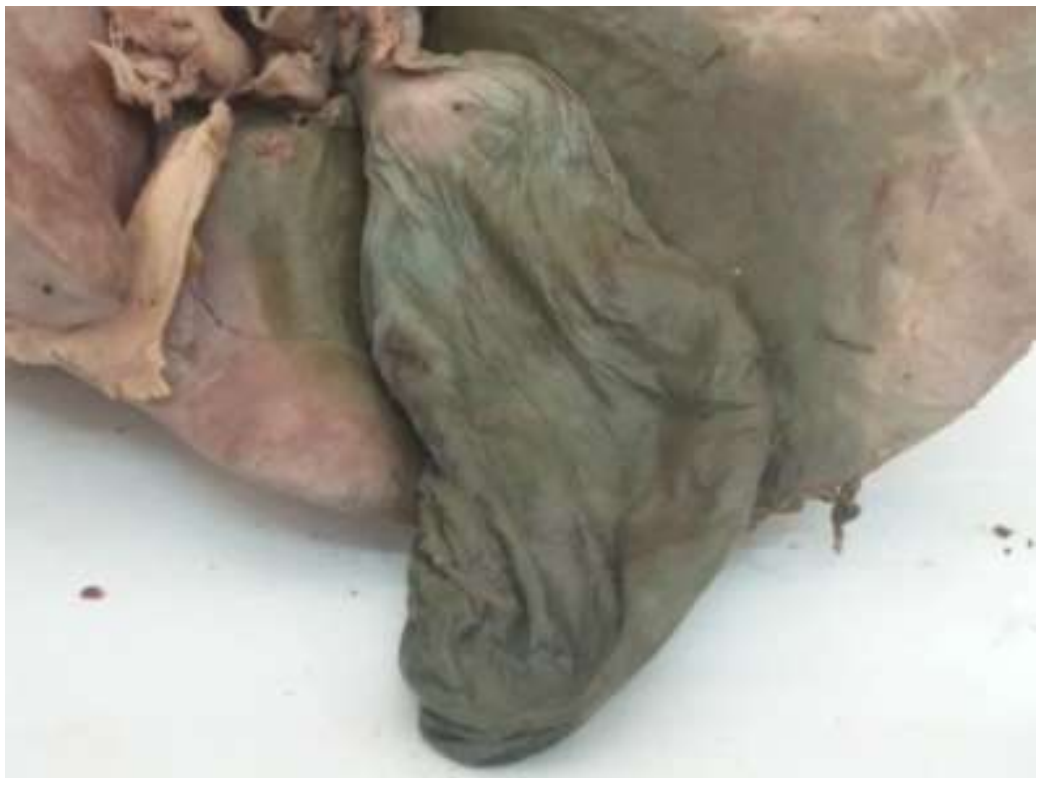

Table: 01. Shape of the gall bladder.

\begin{tabular}{|l|l|l|}
\hline SHAPE & NUMBER & PERCENTAGE \\
\hline PEAR & 80 & $80 \%$ \\
\hline FLASK & 10 & $10 \%$ \\
\hline CYLINDRICAL & 4 & $04 \%$ \\
\hline HOUR GLASS & 2 & $02 \%$ \\
\hline RETORT & 2 & $02 \%$ \\
\hline IRREGULAR & 2 & $02 \%$ \\
\hline
\end{tabular}

Table: 02. External variations of the gall bladder.

\begin{tabular}{|l|l|l|l|}
\hline External variation & Position of folding & Number of specimens & percentage \\
\hline \multirow{2}{*}{ Folded fundus } & Anteriorly & 01 & $01 \%$ \\
\cline { 2 - 4 } & posteriorly & 01 & $01 \%$ \\
\hline \multirow{2}{*}{ Folded neck } & Anteriorly & 02 & $01 \%$ \\
\cline { 2 - 4 } & Posteriorly & 02 & $01 \%$ \\
\hline Folded Fundus and Neck & Posteriorly & 02 & $02 \%$ \\
\hline
\end{tabular}

Table: 03. Showing length and transverse diameters of gall bladder as recorded by other authors

\begin{tabular}{|l|l|l|l|}
\hline Sr. No. & Authors & Length Of Gall Bladder & Transverse Diameter Of Gall Bladder \\
\hline 1 & Turner\&Fulcher/(2000) 3 & $10 \mathrm{~cm}$ & $3-5 \mathrm{~cm}$ \\
\hline 2 & Chari \&Shah $(2008) 5$ & $7-5 \mathrm{~cm}$ & $2-5 \mathrm{~cm}$ \\
\hline 3 & Vakili\& Pomfret $(2008)$ & $7-4 \mathrm{~cm}$ & $4 \mathrm{~cm}$ \\
\hline 4 & Jaba Rajguru et al2 (2012) & $5-12 \mathrm{~cm}$ & $2.5-5 \mathrm{~cm}$ \\
\hline 5 & Present study $(2016)$ & $7-10 \mathrm{~cm}$ & $2-5 \mathrm{~cm}$ \\
\hline
\end{tabular}

